\title{
Transgenic Mice Expressing the Intracellular Domain of the p75 Neurotrophin Receptor Undergo Neuronal Apoptosis
}

\author{
Marta Majdan, ${ }^{2}$ Christian Lachance, ${ }^{1}$ Andrew Gloster, ${ }^{2}$ Raquel Aloyz, ${ }^{2}$ Christine Zeindler, ${ }^{1}$ Shernaz Bamji, ${ }^{2}$ \\ Asha Bhakar, ${ }^{1}$ Daniel Belliveau, ${ }^{2}$ James Fawcett, ${ }^{1}$ Freda D. Miller, ${ }^{1,2}$ and Philip A. Barker ${ }^{1}$ \\ 1,2Center for Neuronal Survival and 2Developmental Neurobiology Laboratory, Montreal Neurological Institute, \\ McGill University, Montréal, Québec, Canada H3A 2B4
}

\begin{abstract}
We have asked whether p $75^{\text {NTR }}$ may play a role in neuronal apoptosis by producing transgenic mice that express the p75 ${ }^{\mathrm{NTR}}$ intracellular domain within peripheral and central neurons. These animals showed profound reductions in numbers of sympathetic and peripheral sensory neurons as well as cell loss in the neocortex, where there is normally little or no p $75^{\mathrm{NTR}}$ expression. Developmental loss of facial motor neurons was not observed, but induced expression of the p $75^{\text {NTR }}$ intracellular domain within adult animals led to increased motor neuron
\end{abstract}

death after axotomy. Biochemical analyses suggest that these effects were not attributable to a p $75^{\mathrm{NTR}}$-dependent reduction in trk activation but instead indicate that the p $75^{\mathrm{NTR}}$ intracellular domain may act as a constitutive activator of signaling cascades that regulate apoptosis in both peripheral and central neurons.

Key words: nerve growth factor; sympathetic neuron; tumor necrosis factor; cell death; NF-kB; jun kinase
Neurotrophins play critical roles in the survival and maintenance of specific neuronal populations during development and into adulthood. Their effects are mediated by trk receptors, which are classical tyrosine kinase receptors activated in response to neurotrophin binding, and by the $\mathrm{p} 75^{\mathrm{NTR}}$, a member of the superfamily of tumor necrosis factor (TNF) receptor-related molecules. Biochemical and genetic analyses have shown that the stereotypical survival and differentiative responses mediated by neurotrophins are attributable to activation of the trk receptors (for review, see Klein, 1994; Greene and Kaplan, 1995).

The physiological role played by the $\mathrm{p} 75^{\mathrm{NTR}}$ is still being determined. One hypothesized function that has gained general acceptance is that p $75^{\mathrm{NTR}}$ acts as an accessory receptor for trkA, increasing the ability of trkA to bind and respond to limiting levels of nerve growth factor (NGF). Biochemical data show that trkA-expressing cells become increasingly responsive to NGF when transfected with $\mathrm{p} 75^{\mathrm{NTR}}$, that numbers of high-affinity NGF binding sites are increased in membranes in which both receptors are coexpressed, and that $\mathrm{p} 75^{\mathrm{NTR}}$-specific antibodies reduce NGF-mediated activation of trkA (Hempstead et al., 1991; Barker and Shooter, 1994; Verdi et al., 1994). p $75^{\text {NTR }}-/-$ mice

Received March 4, 1997; revised June 6, 1997; accepted July 1, 1997.

This work was supported by grants from the Canadian Neurosciences Network Program (to P.A.B. and F.D.M.), from the Medical Research Council (MRC) of Canada (to P.A.B. and F.D.M.), and from the Fond de la Recherche en Santé du Québec (to P.A.B.). C.L. was supported by a fellowship from the Fond de la Recherche en Santé du Québec, A.G. by a Canadian Parkinson's Foundation Fellowship, R.A. by a Canadian Neurosciences Network Fellowship, S.B. by an MRC Studentship, A.B. by a studentship from the Rick Hansen Man in Motion Foundation, and D.B. by a joint MRC-Genentech Fellowship. P.B. and F.M. are Scholars of the Killam Foundation, and P.B. is an MRC Scholar. We are gratef ul to Audrey Speelman for excellent technical assistance, to Dr. John Hiscott for advice on NF-kB assays, and to Dr. David Kaplan for supplying antibodies and for helpful comments on this manuscript.

Correspondence should be addressed to Dr. Freda D. Miller or Dr. Philip A. Barker, Center for Neuronal Survival, Montreal Neurological Institute, McGill University, 3801 University Avenue, Montréal, Québec, Canada H3A 2B4.

Dr. Belliveau's present address: NeuroVir Research \#100-2386 East Mall, Vancouver, BC, Canada V6T 1 Z3.

Copyright (C) 1997 Society for Neuroscience $0270-6474 / 97 / 176988-11 \$ 05.00 / 0$ show reductions in NGF-mediated survival (Davies et al., 1993), a trkA-dependent response, consistent with the hypothesis that $\mathrm{p} 75^{\mathrm{NTR}}$ plays some role in enhancing trkA activation. However, p $75^{\text {NTR }}$ is also capable of autonomous activation of signal transduction cascades. In $\mathrm{p} 75^{\mathrm{NTR}}$-expressing fibroblasts and in PC12 cells, p $75^{\text {NTR }}$ ligation results in increased sphingomyelinase activity and accumulation of the potent lipid second messenger, ceramide (Dobrowsky et al., 1994, 1995). NGF-dependent activation of the NF-kB transcriptional complex occurs in both cultured Schwann cells and in L929 fibroblasts transfected with p75 NTR (Carter et al., 1996), and NGF-dependent activation of jun kinase occurs within cultured rat oligodendrocytes that express $\mathrm{p} 75^{\mathrm{NTR}}$ but not trkA (Casaccia-Bonnefil et al., 1996). Both ceramide accumulation and jnk activation are correlated with apoptotic stimuli in a number of systems, and several recent results suggest that $\mathrm{p} 75^{\mathrm{NTR}}$ may play a role in regulating cellular apoptosis. For example, sensory neurons that normally apoptose very rapidly when deprived of neurotrophin show reduced rates of neurotrophin withdrawal-induced cell death if $\mathrm{p} 75^{\mathrm{NTR}}$ levels are reduced (Barrett and Bartlett, 1994; K.-F. Lee, personal communication). Cell death within the developing avian retina is reduced by antibodies that block NGF binding to p $75^{\text {NTR }}$ (Frade et al., 1996), and cultured oligodendrocytes that express $\mathrm{p} 75^{\mathrm{NTR}}$ undergo increased apoptosis in response to NGF, an effect that can be reduced by using $\mathrm{p} 75^{\mathrm{NTR}}$-blocking antibodies (CasacciaBonnefil et al., 1996). Thus, the available data suggest that NGF working through $\mathrm{p} 75^{\mathrm{NTR}}$ can have a positive or a negative influence on cell survival and that the nature of this effect may depend on the cellular coexpression or coactivation of trkA.

Despite recent advances in this area, the consequences of p $75^{\text {NTR }}$ signaling within neurons remain virtually unknown. This is partially because of the paucity of neuronal systems in which activation of $\mathrm{p} 75^{\mathrm{NTR}}$ signaling can be studied readily and reliably. To address this, we have exploited findings made with truncated intracellular domains of TNF-R1 and fas, members of the TNF receptor superfamily that show weak intracellular homologies to 
p75 NTR. Truncated TNF-R1 produces cellular apoptosis when overexpressed, and the fas intracellular domain can potentiate the TNF-R1 response (Boldin et al., 1995a), both apparently by acting as constitutive activators of their signaling cascades. Reasoning that a similar truncated form of p $75^{\mathrm{NTR}}$ might activate signaling pathways within neurons, we created transgenic mice in which the intracellular domain of $\mathrm{p} 75^{\mathrm{NTR}}$ is expressed within peripheral and central neurons in the hopes of revealing neuronal effects of $\mathrm{p} 75^{\mathrm{NTR}}$ signaling. Our results indicate that the $\mathrm{p} 75^{\mathrm{NTR}}$ does, indeed, act as a constitutive signaling activator; expression of $\mathrm{p} 75^{\mathrm{NTR}}$ results in cell death both in neurons that normally express $p 75^{\text {NTR }}$ as well as in neurons that do not normally express the receptor. Expression of the intracellular domain after injury results in atypical motor neuron death in adult animals, demonstrating that the effects of $\mathrm{p} 75^{\mathrm{NTR}}$ are not limited to a particular developmental time span. Together, these results demonstrate that $\mathrm{p} 75^{\mathrm{NTR}}$ is capable of activating signaling cascades that regulate neuronal apoptosis.

\section{MATERIALS AND METHODS}

Creation of transgenic animals, genotyping, and breeding. A T $\alpha 1$ minigene cloning cassette was constructed in which the $1.1 \mathrm{~kb} \mathrm{~T} \alpha 1 \alpha$-tubulin promoter (Gloster et al., 1994) was separated from SV40 intron and polyadenylation sites by a short polylinker. For the T $\alpha 1$ :intracellular domain (ICD) construct, a cDNA encoding an initiator methionine, followed by amino acids $276-425$ of the rat p75 NTR (Radeke et al., 1987), was subcloned into the polylinker. Completed minigenes were purified free of vector sequence and microinjected into pronuclei to produce founder transgenic animals at the Canadian NeuroScience Network Transgenic Core Facility (McGill University). Genotyping was performed on tail (postnatal animals) or hindlimb (embryos) DNA by Southern blotting with a fragment of the T $\alpha 1 \alpha$-tubulin promoter sequence or by PCR with primers derived from the T $\alpha 1 \alpha$-tubulin promoter and $\mathrm{p} 75^{\mathrm{NTR}}$ sequence. Seven lines of T $\alpha 1$ :ICD mice were identified; four of these were characterized to a moderate degree, and two were examined in detail (4163 T $\alpha 1: \mathrm{ICD}$ and $4173 \mathrm{~T} \alpha 1: \mathrm{ICD})$. For some studies T $\alpha 1$ :ICD lines were crossed to mice carrying a separate transgene in which the T $\alpha 1 \alpha$-tubulin promoter drives expression of nuclear LacZ (Gloster et al., 1994; Bamji and Miller, 1996). The resultant double transgenic lines were designated $4163 \mathrm{~T} \alpha 1: \mathrm{ICD} \times \mathrm{T} \alpha 1$ :nlacZ and 4173 T $\alpha 1: \mathrm{ICD} \times \mathrm{T} \alpha 1:$ nlacZ .

Creation of stable PC12 sublines. pRC-CMV (Invitrogen, San Diego, CA) driving expression of the truncated intracellular domain of rat p $75^{\text {NTR }}$ described above was transfected into PC12 cells, using Lipofectamine (Life Technologies, Gaithersburg, MD), and stable clones were selected in $400 \mu \mathrm{g} / \mathrm{ml} \mathrm{G} 418$. Sixteen clones were analyzed for expression of the p75 NTR - ICD by immunoblot, as described below, and six lines showing expression were retained. The results shown in Figure 7 were repeated in two separate clonal lines.

Animals and surgical procedures. For biochemistry, animals were anesthetized with sodium pentobarbital $(35 \mathrm{mg} / \mathrm{kg})$, and tissues were removed immediately and processed for immunoblots. For morphometric analyses, animals were anesthetized with sodium pentobarbital $(35 \mathrm{mg} /$ $\mathrm{kg}$ ) for $30 \mathrm{~min}$, and ganglia were removed and immersion-fixed in $4 \%$ paraformaldehyde in phosphate buffer (PB) for $1 \mathrm{hr}$ to overnight at $4^{\circ} \mathrm{C}$ (for morphometric analysis of peripheral ganglia) or in $1.6 \%$ glutaraldehyde in $0.1 \mathrm{M} \mathrm{PB}, \mathrm{pH} 7.3$ (for electron microscopy). For morphometric analysis of the cortex, animals were perfused transcardially with $4 \%$ paraformaldehyde in PB. Subsequent to transcardial perfusion, the brains were removed and post-fixed in $4 \%$ paraformaldehyde in PB. The brains subsequently were cryoprotected in graded sucrose solutions, sectioned on the cryostat, and stained with cresyl violet.

For facial nerve lesion studies, animals were anesthetized with Metophane, and the main branch of the facial nerve was resected as it exited the stylomastoid foramen, taking care not to injure the adjacent blood vessels. Seven days after axotomy, animals were anesthetized with sodium pentobarbital and transcardially perfused with $4 \%$ paraformaldehyde. Brains were cryoprotected in graded sucrose solutions and sectioned on the cryostat. In total, three control and transgenic animals from each line were analyzed.

Histological and morphometric analyses. Embryos were prepared for $\beta$-galactosidase staining essentially as described (Gloster et al., 1994). In brief, embryos were fixed for $60 \mathrm{~min}$ at $4^{\circ} \mathrm{C}$ in freshly prepared $4 \%$

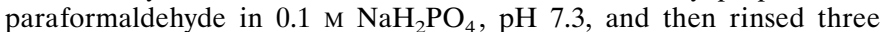
times in $0.1 \mathrm{M} \mathrm{NaH}_{2} \mathrm{PO}_{4}, \mathrm{pH} 7.3,2 \mathrm{mM} \mathrm{MgCl}_{2}, 0.01 \%$ sodium deoxycholate, and $0.02 \%$ Nonidet $\mathrm{P} 40$. The staining reaction was performed in rinse buffer supplemented with $1 \mathrm{mg} / \mathrm{ml} \mathrm{X}$-gal, $5 \mathrm{~mm} \mathrm{~K}_{3} \mathrm{Fe}(\mathrm{CN})_{6}$, and 5 $\mathrm{mm} \mathrm{K}_{4} \mathrm{FE}(\mathrm{CN})_{6}$, typically for $3-5 \mathrm{hr}$ at $37^{\circ} \mathrm{C}$. Embryos were post-fixed up to $48 \mathrm{hr}$ in $4 \%$ paraformaldehyde. For sectioning, tissues were cryopreserved and cryosectioned. For terminal deoxynucleotidyl transferasemediated dUTP-biotin nick end labeling (TUNEL) analysis, embryos first were stained in X-gal, post-fixed for $24 \mathrm{hr}$ in $4 \%$ paraformaldehyde, cryosectioned, and then TUNEL-labeled by an Apoptag kit (Oncor, Gaithersburg, MD) as per the manufacturer's instructions.

Morphometric analyses of motor and sensory neurons were performed with a computer-based image analysis system that prevents double measurement of profiles (Biocom, Paris, France). For counts of facial motor neurons, cryoprotected brains were frozen and mounted for cryosectioning, and $16 \mu \mathrm{m}$ coronal sections were collected through the extent of the facial nuclei. Slides subsequently were stained with cresyl violet to visualize nuclei, and all of the neuronal profiles with a distinct nucleolus were counted on every fifth section. Quantitative comparisons were made, in all cases, between injured facial motor neurons on one side and the contralateral, uninjured motor neurons on the other side. Similar sections through the facial nucleus were analyzed for neuronal size. For determination of sensory neuron number, L3, L4, and L5 dorsal root ganglia (DRG) were serial-sectioned at $7 \mu \mathrm{m}$, and neurons containing a distinct nucleolus were counted in every fourth section, as per Coggeshall (Coggeshall, 1992; Coggeshall and Lekan, 1996). This approach does not correct for split nucleoli. For comparisons of cortical neuron number, cresyl violet-stained coronal sections at the appropriate level were photographed, and the total number of neuronal profiles was counted in $530-\mu \mathrm{m}$-wide strips that extended from pia to corpus collosum.

For electron microscopy of the dorsal cutaneous nerve (DCN), the DCN was dissected from adult animals, immersion-fixed overnight in $1.6 \%$ glutaraldehyde in $0.1 \mathrm{M} \mathrm{PB}, \mathrm{pH} 7.3$, post-fixed in $1 \% \mathrm{OsO}_{4}$ in sodium cacodylate, and dehydrated in a series of ascending ethanol gradients $(70,85,95$, and $100 \%)$. Samples were cleared in acetone, infiltrated, and embedded in spurr resin. Sections were collected on Formvar-coated 50 mesh copper grids, stained with lead citrate and uranyl acetate, and examined and photographed on a Hitachi H7100 transmission electron microscope. Myelinated axons were identified by their darkly stained sheaths, whereas unmyelinated axons were identified by their light appearance relative to the surrounding Schwann cell cytoplasm. These cross sections of the DCN were photographed and montaged, and the total number of myelinated and unmyelinated axons was counted. Statistical results were expressed as mean value \pm SEM and were tested for significance by the one-tailed Student's $t$ test for paired differences.

Immunoblotting, immunoprecipitation, jnk assays, and NF-kB assays. For immunoblotting for the $\mathrm{p} 75^{\mathrm{NTR}}-\mathrm{ICD}$, whole brains from $\mathrm{P} 20$ animals were homogenized in $20 \mathrm{~mm}$ Tris, $\mathrm{pH} 8.0,154 \mathrm{~mm} \mathrm{NaCl}, 10 \%$ glycerol, $1 \%$ Nonidet P-40, $1 \mu \mathrm{g} / \mathrm{ml}$ leupeptin, $100 \mu \mathrm{M}$ phenylmethylsulfonyl fluoride, $5 \mathrm{~mm}$ phenanthroline, and $1 \mathrm{~mm}$ orthovanadate in a polytron, spun for $30 \mathrm{~min}$ at $12,000 \mathrm{rpm}$ in a Beckman JA-14 rotor to remove insoluble material, and then assayed for protein content by the BCA assay (Pierce, Rockford, IL). Soluble brain extract $(20 \mu \mathrm{g})$ from NP40 lysates was separated on $12 \%$ SDS-PAGE, transferred to nitrocellulose, and immunoblotted with $\alpha \mathrm{P} 1$, a rabbit polyclonal antibody directed against the $\mathrm{p} 75^{\mathrm{NTR}}$ intracellular domain (Barker et al., 1994). So that trk receptors in brain tissue could be characterized, trk receptors were immunoprecipitated from lysates prepared from neonatal or adult brains with the pan-trk antibody 203 (Hempstead et al., 1992), separated by 7.5\% SDS-PAGE, and then immunoblotted either with 4G10, an antiphosphotyrosine antibody, or with pan-trk 203 , TrkB ${ }_{\text {out }}$ (Kaplan et al., 1993) or TrkC $_{\text {in }}$ (Belliveau et al., 1997) to detect total trk, trkB, or trkC, respectively. For analysis of whole-cell lysate tyrosine phosphorylation, lysates of neural tissue were separated by $7.5 \%$ SDS-PAGE and immunoblotted with $4 \mathrm{G} 10$.

NF-kB and jun kinase activity assays were performed on nuclear and cytoplasmic fractions, respectively, of embryonic day 16 (E16), E17, and E18 transgenic and wild-type littermates. NF-kB levels were determined by electrophoretic mobility shift assays, using HIV-LTR as a probe, essentially as described (Singh and Aggarwal, 1995). Jun kinase assays were performed by using a GST-jun fusion protein encoding amino acids 1-91 of human c-jun, as described in Westwick and Brenner (1995). 
A

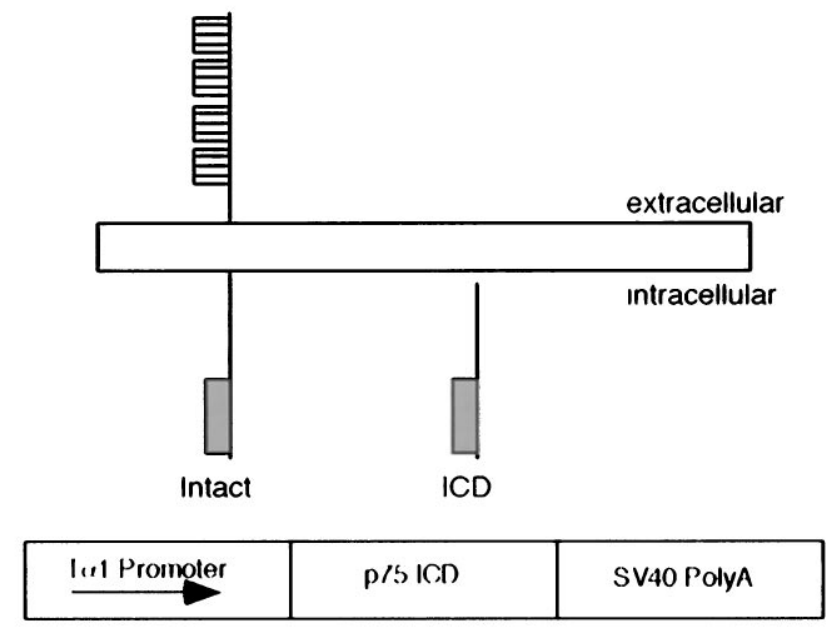

B

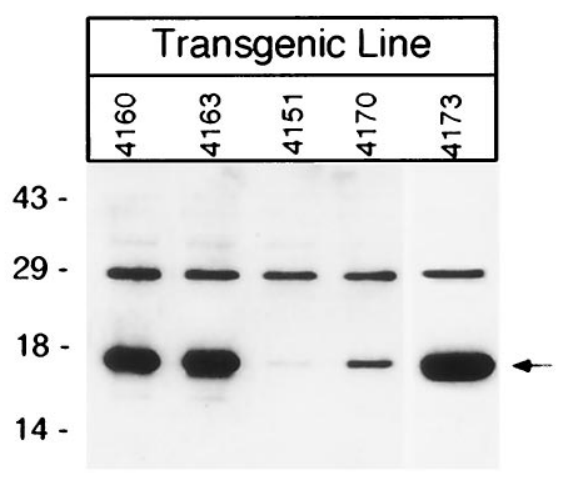

Figure 1. Expression of the T $\alpha 1$ :ICD in the brains of transgenic mice. $A$, A T $\alpha 1$ minigene cloning cassette was constructed in which the $1.1 \mathrm{~kb}$ T $\alpha 1$ $\alpha$-tubulin promoter was separated from an SV40 intron and polyadenylation sites by a cDNA encoding amino acids $276-425$ of the rat p75 ${ }^{\mathrm{NTR}}$. The resultant minigene was purified free from vector sequence and microinjected to produce founder transgenic animals at the Canadian NeuroScience

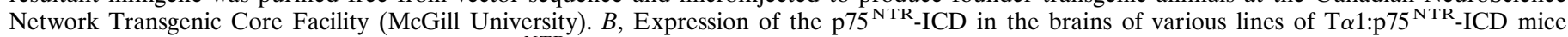
detected by immunoblot. The position of the p $75^{\mathrm{NTR}_{-}}$ICD is indicated by an arrow (right), and molecular weight standards are indicated (left).

\section{RESULTS}

Recent studies suggest a role for $\mathrm{p} 75^{\mathrm{NTR}}$ in the regulation of cellular apoptosis (Barrett and Bartlett, 1994; Casaccia-Bonnefil et al., 1996). To determine whether $\mathrm{p} 75^{\mathrm{NTR}}$ is capable of promoting neuronal apoptosis and to begin to examine molecular mechanisms underlying such effects, we expressed the cytoplasmic domain of the $\mathrm{p} 75^{\mathrm{NTR}}$ in neurons of transgenic mice, using a minigene composed of the $1.1 \mathrm{~kb} \mathrm{~T} \alpha 1 \alpha$-tubulin promoter, an open reading frame encoding the intracellular domain of rat p75 ${ }^{\text {NTR }}$ (amino acids 276-425), and an SV40 intron and polyadenylation signal (Fig. $1 A$ ). The T $\alpha 1 \alpha$-tubulin promoter produces robust expression concomitant with or shortly after neuronal terminal mitosis and is maximally active during periods of process extension (Gloster et al., 1994). T $\alpha 1$-driven expression decreases to lower levels in the mature nervous system (Bamji and Miller, 1996) and is reinduced after axonal injury (Gloster et al., 1994; Wu et al., 1997).

Genotyping revealed that T $\alpha 1: \mathrm{ICD}$ animals were underrepresented in litters, suggesting some embryonic lethality of the transgenic animals. Nonetheless, many animals survived to term and developed into fertile adults. Immunoblot analysis showed p75 ${ }^{\text {NTR }}$-ICD expression in neonatal brains of various $T \alpha 1$ : p75 NTR -ICD lines, with levels of expression varying considerably (Fig. $1 B$ ). Transgene-positive animals from these lines exhibited a phenotype indicative of nervous system deficits, including a general lack of coordination. By the third postnatal week T $\alpha 1: \mathrm{ICD}$ mice exhibited ptosis, and several animals displayed selfmutilation, consistent with defects in sympathetic and sensory innervation, respectively. To examine the cellular basis for these defects, we chose the 4163 and 4173 T $\alpha 1$ :p75 ${ }^{\text {NTR }}$-ICD lines for detailed analysis.

\section{p75 ${ }^{\text {NTR }}$-ICD mice have deficits in sympathetic and sensory neurons}

Because ptosis indicates a deficit in sympathetic innervation, we first examined the sympathetic superior cervical ganglia (SCG) from transgenic and nontransgenic littermates. To characterize the sympathetic deficit, we mated T $\alpha 1$ ICD mice with homozy- gous $\mathrm{T} \alpha 1$ :nlacZ mice in which a $\beta$-galactosidase marker gene is expressed pan-neuronally (Gloster et al., 1994; Bamji and Miller, 1996). Figure $2 A$ shows SCG from p $75^{\text {NTR }}$-ICD-positive and negative littermates that were removed at postnatal day $1(\mathrm{P} 1)$, which precedes the period of naturally occurring cell death in the murine SCG (Crowley et al., 1994). The SCG from p75 NTR-ICDexpressing animals were greatly reduced in size, and X-gal staining indicated that these SCG contained many fewer $\beta$-galactosidase positive nuclei; in several T $\alpha 1$ :p $75^{\text {NTR }}$-ICD animals, distinct SCG could not be identified for dissection. To confirm this apparent neuronal loss within the SCG, we dissected SCG from adult T $\alpha 1: \mathrm{ICD}$ animals and sectioned and stained them with cresyl violet. The transgenic adult SCG were greatly reduced in size, as compared with their wild-type counterparts, because of a dramatic loss of neurons from these ganglia (Fig. $2 B, C)$.

The T $\alpha 1 \alpha$-tubulin promoter becomes active concomitant with or immediately after terminal mitosis, suggesting that neuronal loss in T $\alpha 1$ :ICD mice reflects a deficit in neuronal survival rather than defects in the developmental progression of neuronal precursors to postmitotic neurons. To confirm this, we examined the development of sensory neurons of the DRG in transgenic versus control mice. DRG neurons are normally born at E10, and detectable T $\alpha 1 \alpha$-tubulin promoter activity is first observed within a subset of the developing DRG by E10.5 and within all DRG neurons by E11.5 (A. Gloster, H. El-Bizri, S. Bamji, and F. D. Miller, unpublished data). At E11.5, there were no apparent differences in the pattern or intensity of X-gal staining of line $4173 \mathrm{~T} \alpha 1: \mathrm{ICD} \times \mathrm{T} \alpha 1:$ nlacZ DRGs relative to their control T $\alpha 1$ : nlacZ littermates (data not shown). In contrast, at E13.5, the DRGs of T $\alpha 1: I C D \times T \alpha 1:$ nlacZ were reduced considerably in size, as indicated by X-gal staining (Fig. $3 A$ ), indicating a loss of neurons within days of transgene induction. To confirm that this decrease in X-gal staining corresponds to a loss of sensory neurons, we determined the number of neurons in the L3, L4, and L5 DRG of control versus line 4173 T $\alpha 1$ :ICD animals (Fig. 3B). To perform this analysis, we serially sectioned L3, L4, and L5 DRGs 


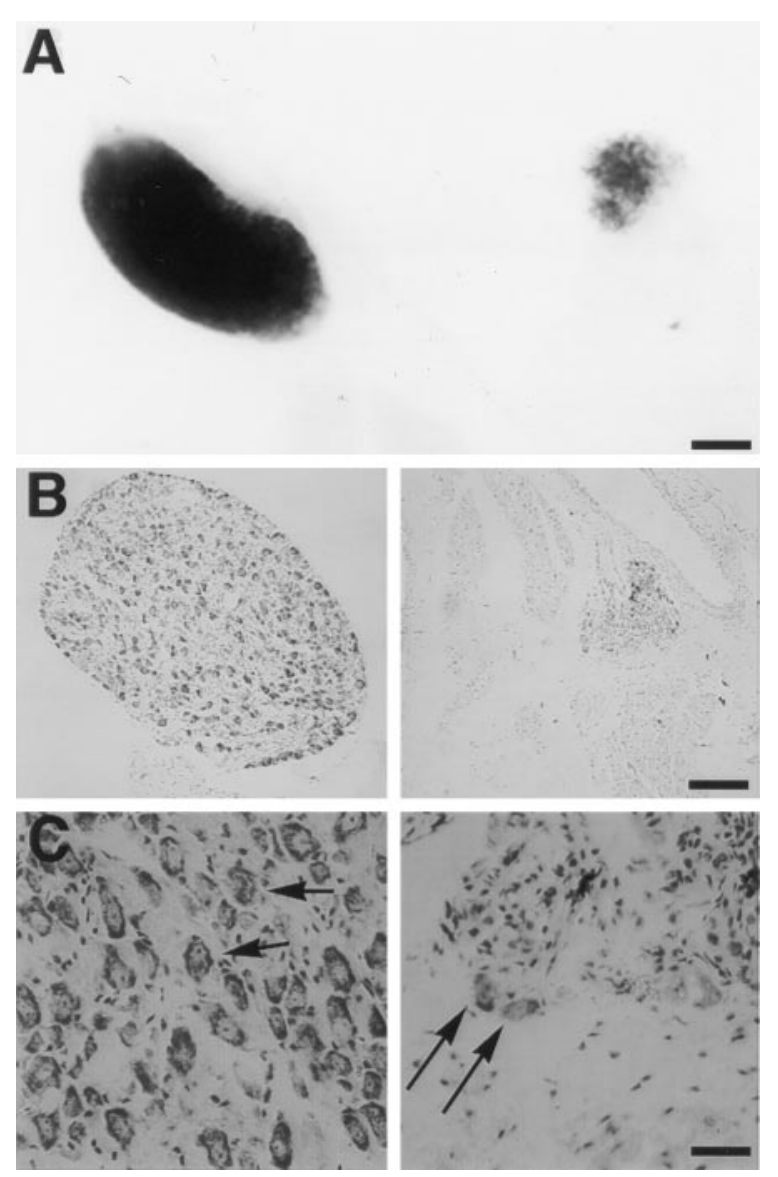

Figure 2. Expression of the p $75^{\mathrm{NTR}}-\mathrm{ICD}$ in developing neurons leads to loss of sympathetic neurons. $A$, Sympathetic superior cervical ganglion (SCG) from a postnatal day $1 \mathrm{~T} \alpha 1$ :nlacZ control mouse (left) and from its T $\alpha 1: I C D \times T \alpha 1$ :nlacZ littermate (line 4173, right) were stained with X-gal to visualize T $\alpha 1$ :nlacZ-expressing neurons. Scale bar, $167 \mu \mathrm{m}$. $B$, Photomicrograph of SCG sections from an adult control (left) or from a line 4173 T $\alpha 1$ :ICD mouse (right) stained with cresyl violet. Scale bar, $84 \mu \mathrm{m}$. $C$, Higher magnification of sections of sympathetic cervical ganglia from a wild-type (left) or from a $4173 \mathrm{~T} \alpha 1$ :ICD mouse (right). Arrows in $C$ indicate sympathetic neurons. Scale bar, $21 \mu \mathrm{m}$.

at $7 \mu \mathrm{m}$, and we counted neurons containing a distinct nucleolus on every fourth section. This analysis demonstrated a loss of $39 \%$ of the DRG neurons within $4173 \mathrm{~T} \alpha 1$ :ICD animals relative to controls $(\mathrm{T} \alpha 1: \mathrm{ICD}=6417 \pm 1359 ;$ controls $=10497 \pm 306 ; n=$ 3 animals each). Thus, the decrease in X-gal staining in the DRG of T $\alpha 1$ :ICD embryos corresponds to a decrease in sensory neuron number.

To define precisely the population of sensory neurons lost in the adult T $\alpha 1$ :ICD mice, we characterized the distribution of axons within cross sections of the DCN of adult animals of lines 4163 and 4173 . The DCN was chosen for these analyses because it is composed almost exclusively of DRG-derived sensory axons (supplying hairy skin of the back) and because shifts in size distributions of axons present within this nerve accurately reflect neuronal losses within the parental DRG. Electron micrographs of the DCN revealed fewer unmyelinated axons within the transgenic versus wild-type DCN (Fig. $4 A-D$ ); counts of axonal profiles revealed that $\sim 50 \%$ of the unmyelinated axons were lost in the p75 ${ }^{\text {NTR }}$-ICD-expressing animals (Fig. $4 E$ : wt, $1644 \pm 292$; line 4173, $656 \pm 147$; line 4163, $830 \pm 246, p<0.05 ; n=4$ animals each). The numbers of myelinated axons did not differ signifi- cantly between transgenic and wild-type DCN, although there was a nonsignificant trend toward fewer myelinated axons in the T $\alpha 1$ :ICD animals (wt, $287 \pm 60$; line 4173, $167 \pm 34$; line 4163, $188 \pm 32, p>0.05 ; n=4$ animals each). The small-caliber unmyelinated axons are derived from the trkA-positive population of sensory neurons (Carroll et al., 1992; Ruit et al., 1992), suggesting a selective loss of NGF-responsive sensory neurons in the T $\alpha 1: \mathrm{ICD}$ mice.

\section{p75 ${ }^{\text {NTR }}$-ICD expression results in neuronal loss within the neocortex}

Sympathetic and sensory neurons lost in the T $\alpha 1$ ICD animals coexpress $\mathrm{p} 75^{\mathrm{NTR}}$ and trkA during development and in maturity, raising the possibility that the effects of the $p 75^{\text {NTR }}$-ICD could be attributable to interference with normal signaling through these receptors. If true, this dominant-negative effect should not be observed in neurons that do not express either $\mathrm{p} 75^{\mathrm{NTR}}$ or trkA. To test this, we examined the neocortex, which lacks trkA expression and in which p $75^{\text {NTR }}$ is expressed only transiently within the subplate (Allendoerfer et al., 1990).

Neuronal counts were performed on two separate regions of the forebrain of wild-type and line 4173 T $\alpha 1$ :ICD animals. One region was a rostral area defined by the position of the lateral ventricles and the medial septum; the other was more caudal, located at the anterior portion of the hippocampal formation. Cresyl violet-stained sections from both of these regions demonstrated that cortical thickness was decreased in T $\alpha 1$ :ICD mice relative to controls (Fig. 5). For quantitation, neuronal counts were performed on $530-\mu \mathrm{m}$-wide strips extending from corpus collosum to pia; this analysis revealed that the decrease in cortical thickness within T $\alpha 1$ :p $75^{\text {NTR }}$-ICD mice reflected a highly signif-
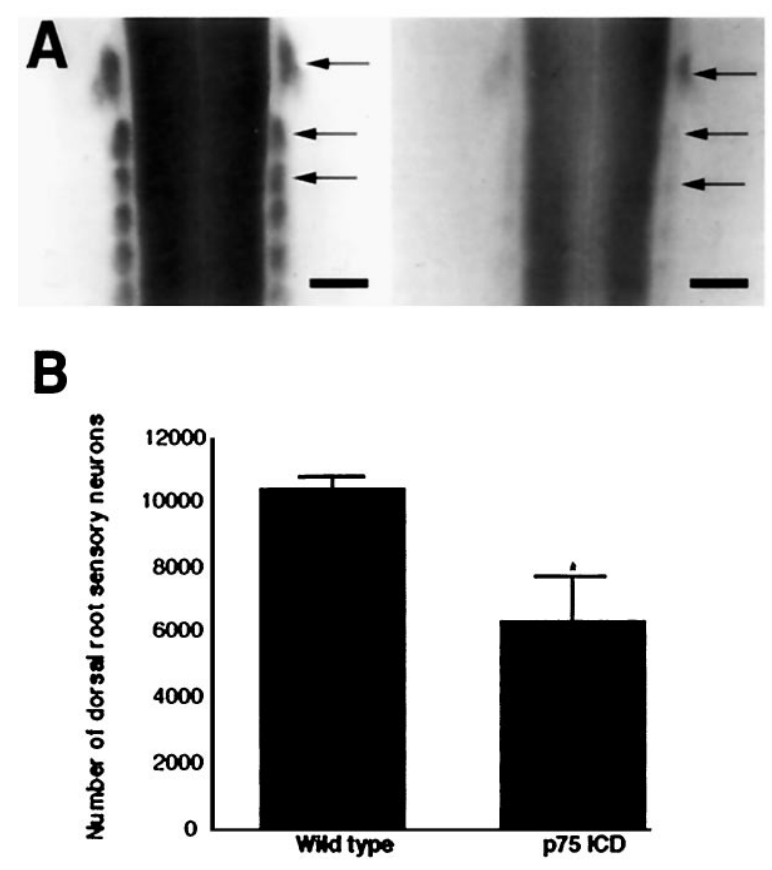

Figure 3. Peripheral sensory neurons are lost in $\mathrm{p} 75^{\mathrm{NTR}}$-ICD transgenic mice. $A$, Whole-mount E13.5 embryos derived from a T $\alpha 1: \mathrm{ICD} \times \mathrm{T} \alpha 1$ : nLacZ cross were stained with X-gal. Arrows indicate DRG within a control embryo (left $)$ and within an embryo carrying the T $\alpha 1$ ICD transgene (right). This example shows a severely affected animal. Scale bar, 400 $\mu \mathrm{m}$. $B$, Counts of neuronal profiles in L3, L4, and L5 DRG of adult wild-type or line 4173 T $\alpha 1$ :ICD animals revealed a significant loss of sensory neurons $\left({ }^{*} p<0.05\right)$. 

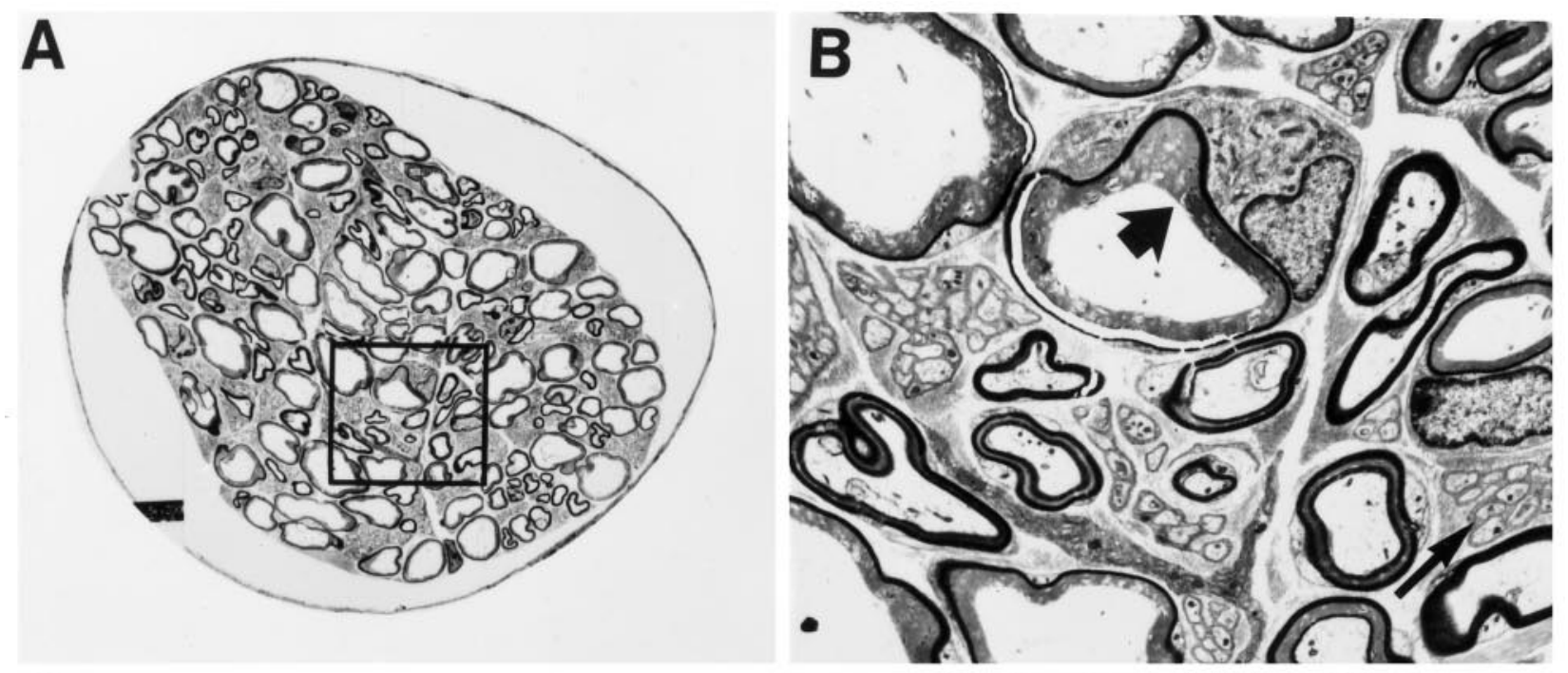

C
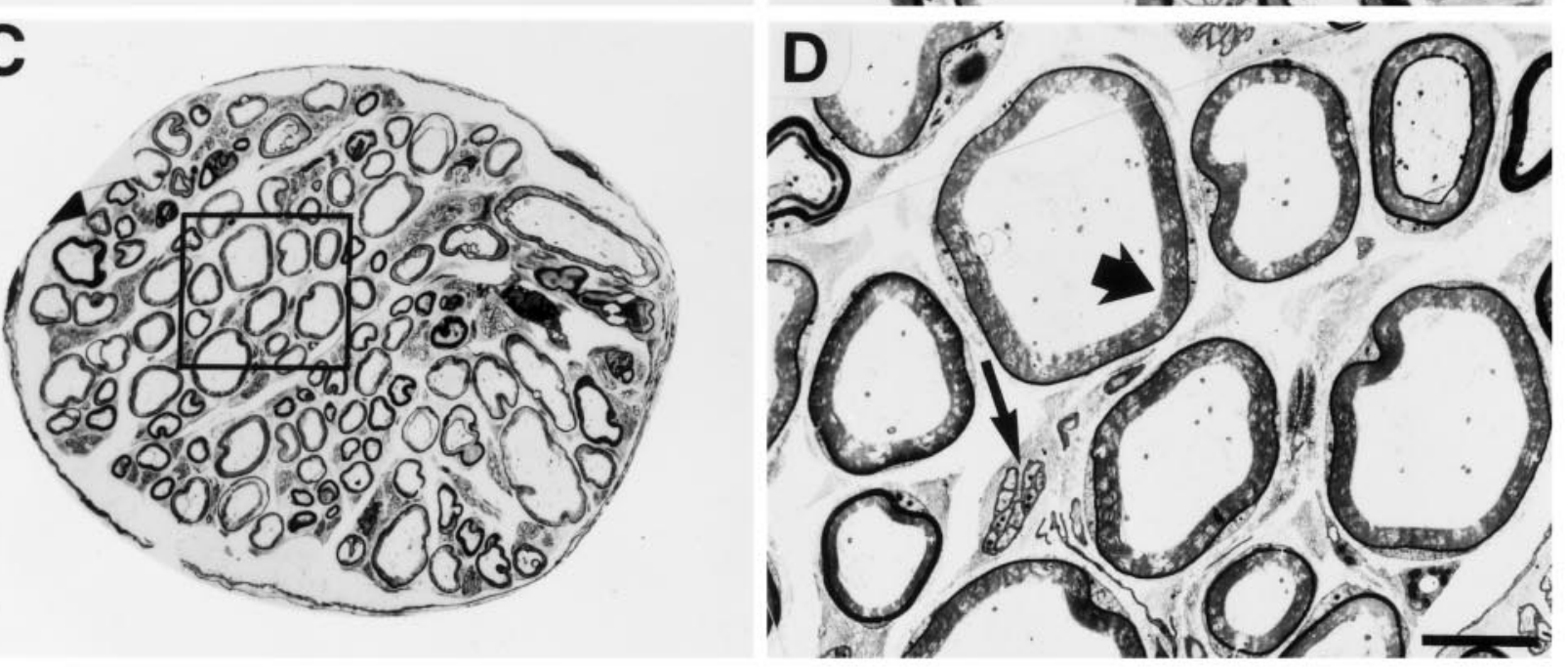

E

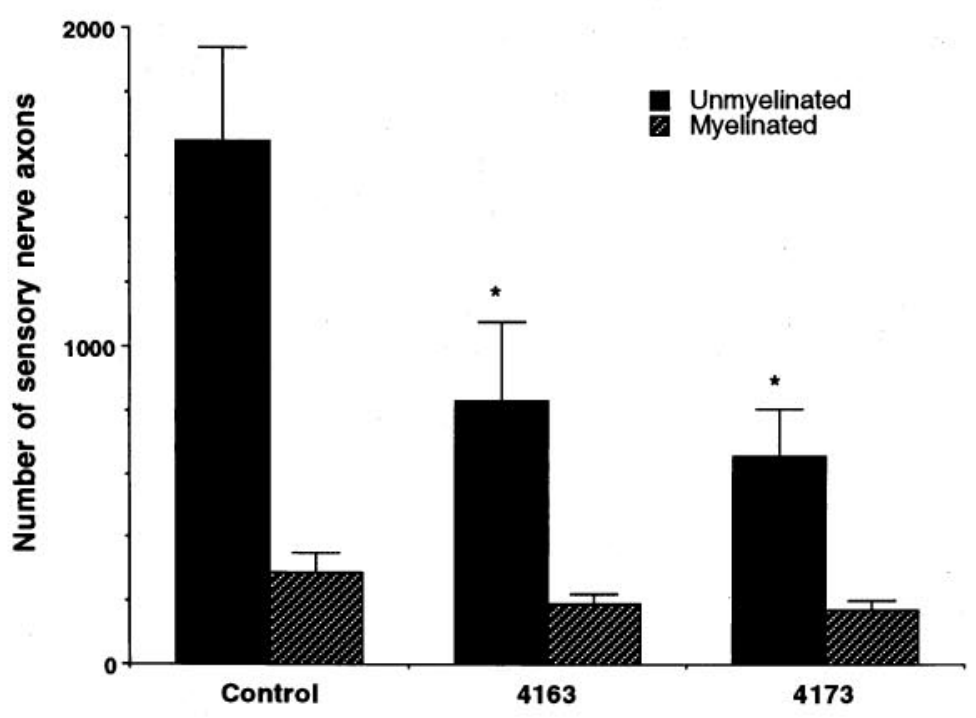

Figure 4. Expression of the p $75^{\mathrm{NTR}}$-ICD leads to loss of unmyelinated sensory axons of the dorsal cutaneous nerve. $A-D$, Cross sections of the dorsal cutaneous nerve of adult control mice $(A, B)$ and adult T $\alpha 1: \mathrm{ICD}$ mice of line $4163(C, D)$, as visualized by electron microscopy. $B, D$, Higher magnifications of the boxes outlined in $A$ and $C$, respectively. Note the selective loss of the smaller fiber unmyelinated axons (thin arrows) relative to the large fiber myelinated sensory fibers (thick arrows). Scale bar, $6 \mu \mathrm{m}$. E, Quantitation of axonal loss demonstrates a selective loss of small unmyelinated sensory fibers in the DCN of T $\alpha 1$ :ICD mice of lines 4163 and 4173 relative to controls $(* p<0.05)$. The myelinated population measured in this analysis includes both the small- and large-caliber myelinated sensory axons. 

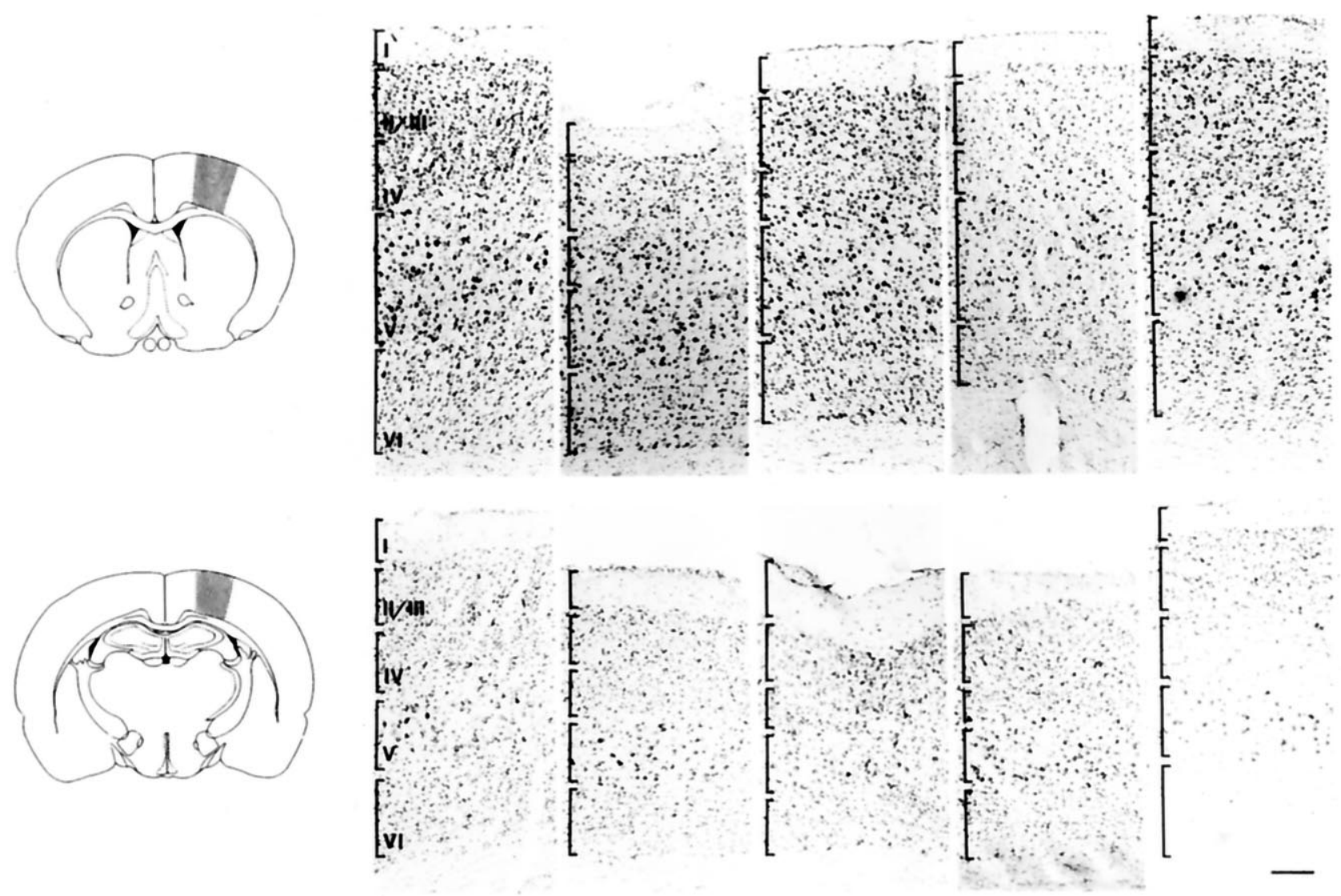


coronal sections of the neocortex of control and transgenic $75^{\mathrm{NTR}}$-ICD animals. Right and far left photographic panels are from control animals, whereas the three inner panels are all from transgenic animals of the 4173 line. The area examined is indicated in the schematic drawings shown at left, with the top panels representing the rostral level of the neocortex and the bottom panels representing the caudal level. Each vertically aligned pair of photomicrographs is derived from the same animal. Brackets in the far left panel indicate approximate boundaries of the different cortical layers. Scale bar, $75 \mu \mathrm{m}$. Neuronal counts reveal a highly significant loss of cortical neurons in the p75 ${ }^{\mathrm{NTR}}$-ICD ( $p<0.001$; see Results).

icant decrease in neuronal number, with $22 \%$ fewer neurons within the rostral region (wt, $3015 \pm 58.3$; line 4173, $2355 \pm 67.7$, $p=0.0005 ; n=3$ animals each) and $26 \%$ neuronal loss in the caudal region (wt, $3133 \pm 145$; line 4173, $2376+15.5, p=0.003$; $n=4 \mathrm{~T} \alpha 1: \mathrm{ICD}$ animals and 3 control animals). This decrease in cortical neuron number in the T $\alpha 1$ ICD mice indicates that the neuronal loss is not limited to trkA- or $\mathrm{p} 75^{\mathrm{NTR}}$-expressing neurons.

\section{Inducible expression of the p75 ${ }^{\text {NTR }}$-ICD leads to death of injured facial motor neurons}

To determine whether the p $75^{\mathrm{NTR}}$-ICD had an effect on motor neurons, we examined the facial motor nucleus in wild-type and T $\alpha 1$ ICD adult mice for deficits in neuronal number or size. Quantitation of cresyl violet-stained sections throughout the extent of the facial nucleus revealed that facial motor neuron size was not altered significantly within T $\alpha 1: \mathrm{p} 75^{\mathrm{NTR}}$-ICD mice (wt, $317.7 \pm 13.8$; line 4173, $329.5 \pm 8.2$; line 4163, 355.3 $\pm 13.9, p>$ $0.05 ; n=3$ animals each) (Fig. $6 A$ ) and that numbers of facial motor neurons were similar in adult controls and transgenic animals of lines 4163 and 4173 ( $p=0.3 ; n=3$ animals each) (Fig. $6 B)$. Thus, unlike peripheral sympathetic and sensory neurons, developing motor neurons are resistant to deleterious effects of p75 ${ }^{\text {NTR }}$-ICD expression.

Our results show that the intracellular domain of the p $75^{\text {NTR }}$ induces cell death of selected developing neuronal populations of neurons, but our results do not address the possibility that acute ICD expression might affect the survival of mature neurons. To examine this possibility, we took advantage of the finding that expression of the T $\alpha 1 \alpha$-tubulin promoter is induced in mature facial motor neurons after facial nerve lesion; promoter activity is maximal 1-3 d after axotomy and thereafter is maintained at high levels until neurons successfully regenerate (Gloster et al., 1994; Wu et al., 1997). To test whether induced expression of the p $75^{\text {NTR }}$ intracellular domain affected survival of mature neurons, we unilaterally resected the facial nerve of adult animals; 1 week later, survival of facial motor neurons was compared between lesioned and unlesioned sides. Consistent with previous findings (Tetzlaff et al., 1991), lesioned and unlesioned facial motor nuclei in control animals showed no significant decrease in relative neuron number (wt uninjured side, $2505 \pm 340$; wt injured side, $2267 \pm 305, p>0.05 ; n=3)$. However, within both the 4163 and 4173 transgenic lines, facial nerve lesion resulted in motor neuron loss of $\sim 40 \%$ (4163 uninjured side, $2675 \pm 140 ; 4163$ injured side, $1573 \pm 66, p<0.05 ; n=3 ; 4173$ uninjured side, $2318 \pm 108 ; 4173$ injured side, $1447 \pm 190, p<0.05 ; n=3$ ) (Fig. 6B). Thus although facial motor neurons were not lost because of developmental expression of the $\mathrm{p} 75^{\mathrm{NTR}}-\mathrm{ICD}$, the 
A

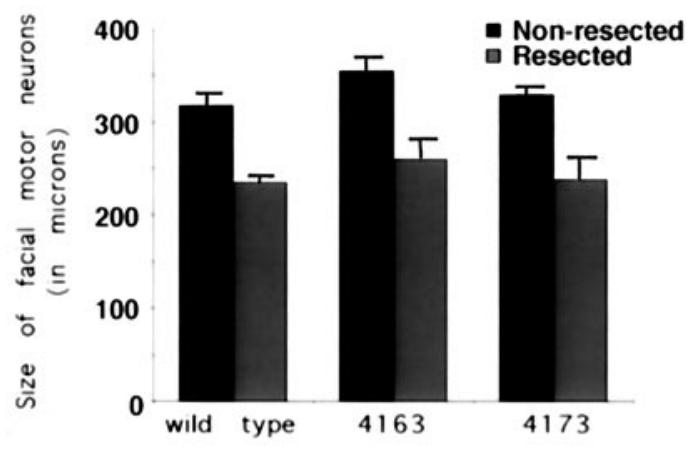

B

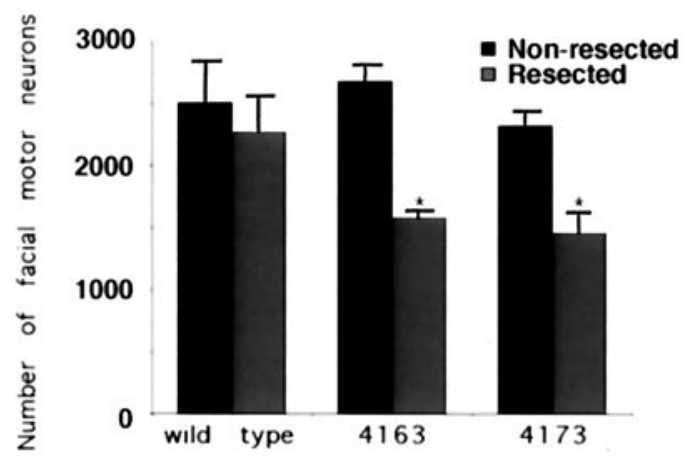

Figure 6. Inducible expression of the p $75^{\mathrm{NTR}}$-ICD results in loss of mature adult facial motor neurons after nerve injury. Coronal sections of facial nuclei were prepared from adult animals subjected to a unilateral facial nerve lesion $7 \mathrm{~d}$ earlier. Sections were stained with cresyl violet, and neuronal counts were performed on every fifth section, as described in Materials and Methods. Neither the size $\left(A\right.$; in $\left.\mu \mathrm{m}^{2}\right)$ nor the number of facial motor neurons $(B)$ is affected significantly by developmental expression of the $\mathrm{p} 75^{\mathrm{NTR}}$-ICD in uninjured neurons, but lesion of the facial nerve results in loss of facial motor neurons in ICD-expressing animals $\left({ }^{*} p<0.05\right)$.

injury-induced expression of this protein resulted in the death of injured adult motor neurons.

\section{p75 ${ }^{\text {NTR }}$-ICD expression does not inhibit activity of intracellular signaling cascades}

The p $75^{\text {NTR }}$-ICD could signal autonomously to mediate apoptosis; alternatively, the ICD could interfere with Trk receptor activation and thereby inhibit a trk-mediated survival signal. To distinguish between these possibilities, we first asked whether the p75 ${ }^{\text {NTR }}$ intracellular domain has any effect on trk receptor autophosphorylation. TrkA-expressing sympathetic and sensory neurons were, in large part, lost from the transgenic animals and, as an alternative, we examined effects of the p $75^{\text {NTR }}$ ICD on trkA using transfected PC12 cells in which the p $75^{\text {NTR }}$-ICD is stably expressed (Fig. $7 A$ ). PC12 cells tolerate the p $75^{\text {NTR }}$-ICD well, and there was no difficulty in producing clones that stably expressed the receptor fragment (data not shown). To test whether the expression of the p $75^{\mathrm{NTR}}$-ICD alters proximal NGFmediated signaling events, we examined trkA autophosphorylation levels over a range of NGF concentrations; Figure $7 B$ shows that the expression of the $75^{\text {NTR }}$-ICD had no apparent effect on levels of NGF-mediated trkA phosphorylation in PC12 cells.

To determine whether the $\mathrm{p} 75^{\mathrm{NTR}}$-ICD perturbed activation of trkB or trkC, we examined levels of endogenous trk receptor activation in the cortex of neonatal (Fig. 7C,D) and adult (Fig. $7 E, F)$ transgenic and control animals. Trk receptors were immunoprecipitated from control or transgenic cortex from both age groups and immunoblotted with antibodies directed against phosphotyrosine or with antibodies specific to either trkB or trkC (data not shown). These studies revealed no difference in endogenous receptor levels or receptor activation between wild-type and transgenic animals, although deficits in neuronal number were observed in these same cortical regions (Fig. $7 E, F$ ). To determine whether neuronal expression of the ICD affected acute activation of trkB, we divided neonatal cortex symmetrically and triturated it, and aliquots were left untreated or exposed to 100 $\mathrm{ng} / \mathrm{ml} \mathrm{BDNF}$ for $10 \mathrm{~min}$. Trk receptors were immunoprecipitated with pan-trk antibody 203 and analyzed for phosphotyrosine content by immunoblot. BDNF-mediated stimulation of trkB was equivalent in both transgenic and wild-type animals (data not shown). Finally, we analyzed lysates of neonatal line 4173 cortex for tyrosine-phosphorylated proteins by immunoblot analysis. These studies revealed no apparent differences between the pattern of proteins bearing tyrosine phosphorylation in the cortex of T $\alpha 1$ :ICD versus control animals (Fig. $7 G$ ). Together, these studies demonstrate that the ability of the p $75^{\text {NTR }}$-ICD to mediate neuronal death is unlikely to be attributable to the inhibition of trk receptor activation.

Recent studies also have demonstrated that a direct signaling cascade mediated by $\mathrm{p} 75^{\mathrm{NTR}}$ may result in the activation of the transcription factor NF-kB and of jun kinase (Carter et al., 1996; Casaccia-Bonnefil et al., 1996). We therefore measured these activities in lysates of T $\alpha 1$ :ICD brains from E16 and E18 embryos in a total of eight litters; although both jnk activity and NF-kB DNA binding activity were detected readily in brain lysates prepared from control or transgenic animals, neither activity was affected by neuronal expression of the p75 ${ }^{\text {NTR }}$-ICD (Fig. 8 $A, B$ ).

\section{DISCUSSION}

Although p $75^{\text {NTR }}$ was cloned over a decade ago, its physiological role remains unclear. Results presented in this paper indicate that the $\mathrm{p} 75^{\mathrm{NTR}}$, like other members of this receptor family, is capable of autonomously signaling to mediate the death of selected populations of developing and injured neurons. Specifically, we have demonstrated that neuronal expression of the truncated intracellular domain (ICD) of $\mathrm{p} 75^{\mathrm{NTR}}$ is sufficient to cause developmental apoptosis of developing sensory and sympathetic neurons in the PNS but not of facial motor neurons. This deficit in neurons was not limited to TrkA- or $\mathrm{p} 75^{\mathrm{NTR}}$-expressing neurons because there are decreased numbers of neurons in the neocortex, where TrkA is not expressed and where $\mathrm{p} 75^{\mathrm{NTR}}$ is expressed only transiently. Moreover, our data indicate that neurons are differentially vulnerable to the ICD at different points in their lifetime; inducible expression of the ICD in injured adult facial motor neurons led to increased neuronal death, whereas the ICD did not affect survival of these same neurons during development. This effect on neuronal apoptosis is not attributable to a direct effect on trk receptors, because trk protein levels and endogenous and induced activation levels all remained the same regardless of the presence or absence of the $\mathrm{p} 75^{\mathrm{NTR}}-\mathrm{ICD}$. On the basis of these data, we believe that the intracellular domain of the p $75^{\text {NTR }}$ is a constitutively active autonomous signaling protein that, in the appropriate neuronal context, will mediate neuronal death. 


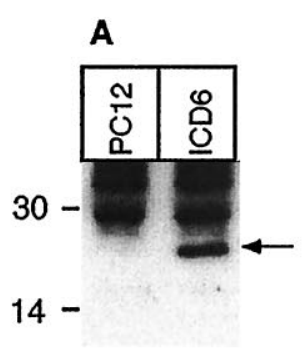

B

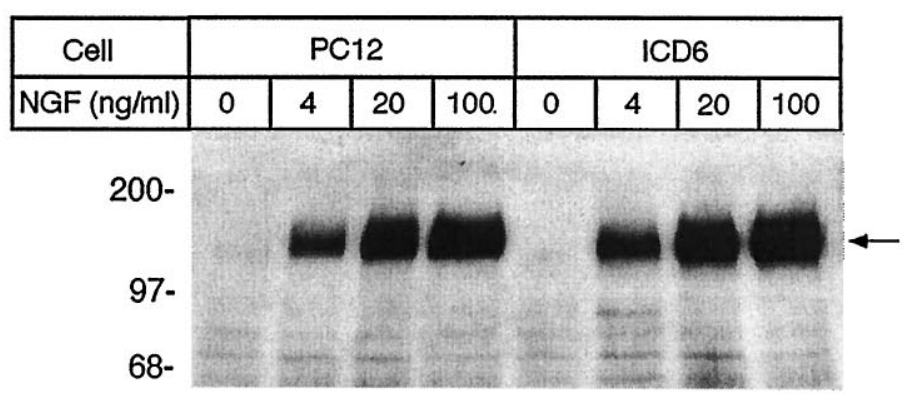

C

D


200-

97.

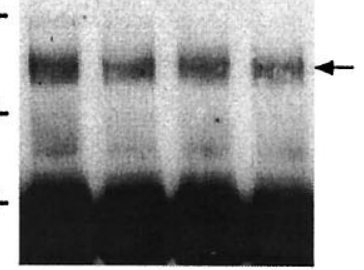

200-

97-

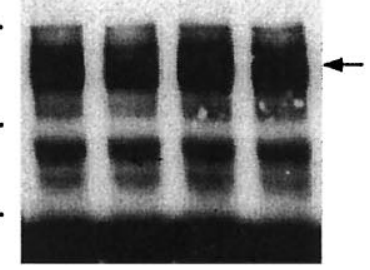

E

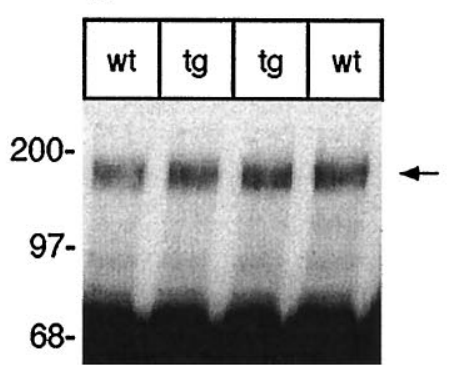

F

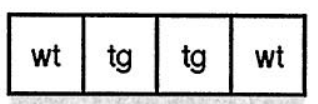

200-

97-

68-



G



200-

97-

$68-$

43-

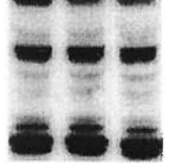

Figure 7. Expression of the $\mathrm{p} 75^{\mathrm{NTR}}$-ICD does not affect trk receptor levels or autophosphorylation. $A, B$, Stable PC12 cells lines created to overexpress the $\mathrm{p} 75^{\mathrm{NTR}}$-ICD were analyzed for trkA autophosphorylation. $A, \mathrm{p} 75^{\mathrm{NTR}}$-ICD was detected by immunoblot in these lines, using $\alpha$ p 1 directed against the $\mathrm{p} 75^{\mathrm{NTR}}$ intracellular domain. $B$, Effects of the $\mathrm{p} 75^{\mathrm{NTR}}$-ICD on NGF-induced trkA autophosphorylation were determined in stable PC12 cell lines subjected to a 5 min treatment with either vehicle or with 4,20 , or $100 \mathrm{ng} / \mathrm{ml} \mathrm{NGF}$. TrkA was immunoprecipitated with anti-pan-trk 203 and subsequently was analyzed for phosphotyrosine content by immunoblot, as described in Materials and Methods. $C-F$, Trk receptor levels and endogenous trk tyrosine phosphorylation are similar in cortices $(C, D)$ of neonatal animals of line 4173 and their control littermates. Cortical lysates were immunoprecipitated with pan-trk antibody 203 and analyzed on immunoblots with anti-phosphotyrosine antibody $4 \mathrm{G} 10(C)$. The same blots subsequently were reprobed with $\operatorname{trkB}_{\text {out }}$, which is specific for trkB $(D)$. No difference in trk activation or levels was observed between control and transgenic animals. $E, F$, Trk receptor levels and endogenous trk tyrosine phosphorylation are similar in the cortex of adult animals of line 4173 and their control littermates. E, Total trk receptors immunoprecipitated from adult cortex were analyzed for phosphotyrosine content by 4G10 immunoblot. $F$, Anti-pan-trk immunoprecipitates from adult animals were immunoblotted to detect total trk receptor levels, using anti-pan-trk 203. $G$, Lysates of neonatal cortex from line 4173 and control animals were analyzed for levels of phosphotyrosine-containing proteins by immunoblot with $4 \mathrm{G} 10$. The arrow in $A$ indicates the p $75^{\mathrm{NTR}}-\mathrm{ICD}$; the arrows in $B-F$ indicate trk receptors. Molecular weight standards are indicated on the left side of each panel.

The structural motif that defines the TNF receptor superfamily is a tandemly repeated extracellular cysteine-rich domain (Banner et al., 1993; Bazan, 1993); many of the receptors within this family play important roles in regulation of proliferation and apoptosis, particularly within the immune system (for review, see Baker and Reddy, 1996). The intracellular domains of these proteins contain no enzymatic activity, and, until recently, the signaling paths that they activated were poorly characterized. The 


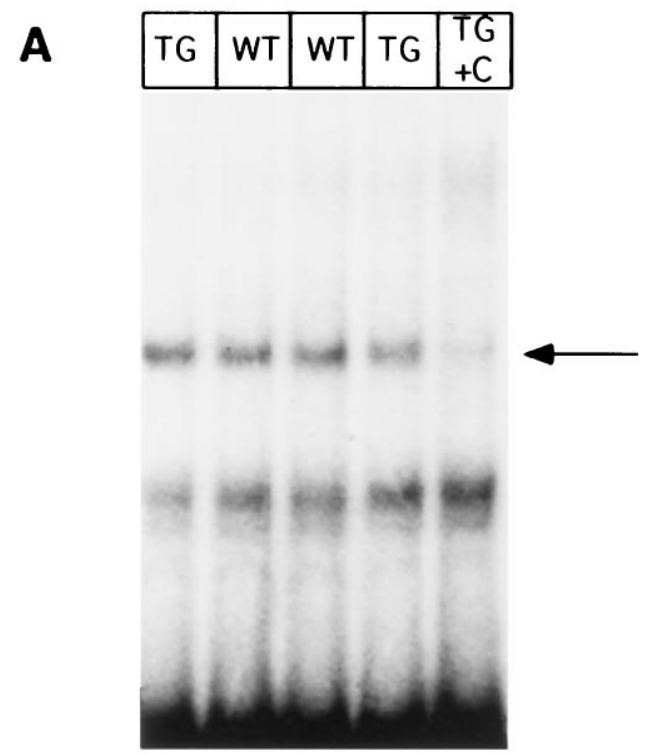

B



Figure 8. Levels of NF-kB and jun kinase activity are not altered in brain lysates of embryonic transgenic animals. $A$, Nuclear extracts from E16 brain lysates were analyzed for NF-kB activity by electrophoretic mobility shift, using an end-labeled $32 \mathrm{bp}$ fragment derived from an HIV-LTR as probe. In lane $5(T G+C), 50 \mathrm{ng}$ of an unlabeled NF-kB element was included with the lane 4 sample to determine specific NF-kB binding complexes (indicated by arrow). Shifted patterns are similar in wild-type (lanes 2 and 3) and in transgenic line 4173 (lanes 1 and 4 ) brains. This is typical of four similar experiments. $B$, Brain lysates from a litter of E16 animals were analyzed for jnk activity, as described in Materials and Methods. Results shown represent mean of assays of individual complete litter ( $n=5$ wild-type and 4 for T $\alpha 1$ :ICD mice) and represent one of three similar experiments.

only intracellular homology identified among members of the TNFR superfamily is a region of 80 amino acids that is found in TNF-R1, fas, DR3, and p75 NTR (Boldin et al., 1995b; Chapman, 1995; Chinnaiyan et al., 1996). In TNF-R1 and fas, this domain is required for ligand-mediated activation of apoptotic pathways, and it therefore has been termed the "death domain" (Tartaglia et al., 1993). A major advance in understanding signaling through this class of receptor has come with the identification of proteins, including TRADD, FADD, and RIP, that interact with TNF-R1 and fas intracellular domains (Chinnaiyan et al., 1995; Hsu et al., 1996). It is now clear that death domain interactions play a critical role in mediating the mobilization of these signaling molecules and the activation of a proteolytic apoptotic cascade (for review, see Nagata, 1997). The fact that a soluble cytoplasmic fragment of
TNF-R1 can provoke cellular apoptosis indicates that overexpressed receptor fragments are capable of activating these signaling proteins (Boldin et al., 1995a).

The analysis of $\mathrm{p} 75^{\mathrm{NTR}}$ signaling in physiologically relevant settings is complicated by the fact that many $p 75^{\text {NTR }}$. expressing cells also express trk receptors that activate distinct signaling cascades in response to the same ligand(s). p75 NTR functionally interacts with trk receptors (Ip et al., 1993; Barker and Shooter, 1994; Verdi et al., 1994), and trk receptor activation may inhibit signaling by $\mathrm{p} 75^{\text {NTR }}$ (Dobrowsky et al., 1995), further complicating the analysis of autonomous p $75^{\text {NTR }}$ signaling cascades. We therefore took a transgenic expression approach to allow us to examine the effects of p75 ${ }^{\text {NTR }}$-dependent signaling in physiologically relevant settings irrespective of ligand binding. The neuronal apoptosis observed in the T $\alpha 1$ :ICD mice is consistent with the hypothesis that the truncated $\mathrm{p} 75^{\mathrm{NTR}}$ fragment does, indeed, act as a constitutive activator of signaling pathways within neurons and suggests that a $\mathrm{p} 75^{\mathrm{NTR}}$-derived signal is capable of mediating apoptosis in a manner similar to other members of this receptor family. Like the intracellular domains of fas and TNF-R1, our evidence suggests that the p $75^{\text {NTR }}$-ICD constitutively may activate a cell death cascade. Mechanisms that may underlie this signaling path include activation of sphingomyelinase, JNK, NF-kB, or members of the TRAF/TRAD family. Our examination of NF-kB or JNK activity in embryonic brains from T $\alpha 1$ :ICD mice did not reveal differences from nontransgenic littermates, but this does not rule out the possibility that activation of these pathways contributes to the transgenic phenotype in subtle cell-specific manners not detected in our biochemical assays. It is possible that changes in neuronal jnk or NF-kB activation that may result from p $75^{\text {NTR }}$-ICD expression are obscured by high levels of activity from unaffected cell types or, alternatively, that high jnk or NF-kB activity occurs in a short developmental window that precedes cell loss. In this regard, the effects of the p75 ${ }^{\mathrm{NTR}}$-ICD show an intriguing cellular specificity, with developmental loss of sympathetic and peripheral sensory neurons and of central neurons of the neocortex. One possible explanation for this is that only these susceptible populations express the signaling partners necessary for mediation of a $\mathrm{p} 75^{\mathrm{NTR}}$ apoptotic cascade. As $\mathrm{p} 75^{\mathrm{NTR}}$ signaling partners are identified and their expression patterns are determined, the basis of the cell specificity of the p75 NTR ICD may become apparent.

Our data do not support the hypothesis that the intracellular p $75^{\text {NTR }}$ fragment acts in a dominant-negative manner, either inhibiting $\mathrm{p} 75^{\mathrm{NTR}}$-dependent survival signal or interfering with the normal action of trkA. If the $\mathrm{p} 75^{\mathrm{NTR}}$ intracellular domain had a dominant-negative effect on $\mathrm{p} 75^{\mathrm{NTR}}$ signaling, the transgenic phenotype should mimic that of the $\mathrm{p} 75^{\mathrm{NTR}}-/-$ mice. However, whereas p75 ${ }^{\text {NTR }}$-ICD transgenics show almost complete loss of sympathetic neurons of the SCG and increased motor neuron loss after injury, in $\mathrm{p} 75^{\mathrm{NTR}}-/-$ mice sympathetic neuron number is not reduced (Lee et al., 1992; Brennan et al., 1996), and reduced motor neuron death is observed after facial nerve lesion (K.-F. Lee, personal communication). Expression of the p $75^{\text {NTR }}$ ICD has no demonstrable effect on ligand-dependent activation of trkA (in stably transfected PC12 cell lines) or trkB (in transgenic brain). It is possible that negative selection has occurred within the transgenic mice such that only those neurons resistant to the effects of the $\mathrm{p} 75^{\mathrm{NTR}}$-ICD are present at the time of our analysis. 
However, results from the PC12 cell sublines suggest that a direct effect of the $\mathrm{p} 75^{\mathrm{NTR}}$-ICD on proximal events in trkA activation is unlikely. Rather, the observation that $\mathrm{p} 75^{\mathrm{NTR}}$-ICD expression results in a highly significant loss of neurons from multiple cortical layers, which normally do not express trkA or p75 NTR (Allendoerfer et al., 1990), suggests that the receptor fragment can have a dominant effect, possibly by constitutively activating an apoptotic signaling cascade.

The findings reported here are consistent with several recent reports indicating that $\mathrm{p} 75^{\mathrm{NTR}}$ may, in some circumstances, play a role in cell death. Supernumerary basal forebrain cholinergic neurons are observed in the $\mathrm{p} 75^{\mathrm{NTR}}-/-$ mice, and their normal developmental loss in wild-type animals is reduced by blocking ligand binding to p $75^{\text {NTR }}$ (Vanderzee et al., 1996). Similarly, cell loss that normally occurs in the developing retina is reduced by reagents that block NGF access to p75 ${ }^{\text {NTR }}$ (Frade et al., 1996). So far, only NGF appears to be capable of mediating this effect; in the avian isthmo-optic nucleus (von Bartheld et al., 1994) and on cultured oligodendrocytes that express p $75^{\text {NTR }}$ but not trkA (Casaccia-Bonnefil et al., 1996), only NGF treatment results in cell death. Together, these results suggest that a normal role of $\mathrm{p} 75^{\mathrm{NTR}}$ may be to aid in the process of developmental apoptosis that occurs within the maturing nervous system. The use of in vivo models such as the T $\alpha 1:$ p $75^{\text {NTR }}$-ICD mice described here should, in the future, allow us to identify functionally relevant $\mathrm{p} 75^{\mathrm{NTR}}$ signaling pathways that contribute to neuronal apoptosis.

\section{REFERENCES}

Allendoerfer KL, Shelton DL, Shooter EM, Shatz CJ (1990) Nerve growth factor receptor immunoreactivity is transiently associated with the subplate neurons of the mammalian cerebral cortex. Proc Natl Acad Sci USA 87:187-190.

Baker SJ, Reddy EP (1996) Transducers of life and death: TNF receptor superfamily and associated proteins. Oncogene 12:1-9.

Bamji SX, Miller FD (1996) Comparison of the expression of a Ta1: nlacZ transgene and Ta1 $\alpha$-tubulin mRNA in the mature central nervous system. J Comp Neurol 374:52-69.

Banner DW, D'Arcy A, Janes W, Gentz R, Schoenfeld H-J, Broger C, Loetscher H, Lesslauer W (1993) Crystal structure of the soluble human $55 \mathrm{kDa}$ TNF receptor-human TNF beta complex: implications for TNF receptor activation. Cell 73:431-445.

Barker PA, Shooter EM (1994) Disruption of NGF binding to the low affinity neurotrophin receptor $\mathrm{p} 75^{\mathrm{LNTR}}$ reduces NGF binding to trkA on PC12 cells. Neuron 13:203-215.

Barker PA, Barbee G, Misko TP, Shooter EM (1994) The low affinity neurotrophin receptor, $\mathrm{p} 75^{\mathrm{LNTR}}$, is palmitoylated by thioester formation through cysteine 279. J Biol Chem 269:30645-30650.

Barrett GL, Bartlett PF (1994) The p75 nerve growth factor receptor mediates survival or death depending on the stage of sensory neuron development. Proc Natl Acad Sci USA 91:6501-6505.

Bazan JF (1993) Emerging families of cytokines and receptors. Curr Biol 3:603-606.

Belliveau DJ, Krivko I, Kohn J, Lachance C, Pozniak C, Rusakov D, Kaplan DR, Miller FD (1997) NGF and NT-3 both activate trkA on sympathetic neurons but differentially regulate survival and neuritogenesis. J Cell Biol 136:375-388.

Boldin M, Mett I, Varfolomeev E, Chumakov I, Shemeravni Y, Camonis J, Wallach D (1995a) Self-association of the death domains of the p55 tumor necrosis factor (TNF) receptor and fas/APO1 prompts signaling for TNF and fas/APO1 effects. J Biol Chem 270:387-391.

Boldin M, Varfolomeev E, Pancer Z, Mett I, Camonis J, Wallach D (1995b) A novel protein that interacts with the death domain of fas/ apoI contains a sequence motif related to the death domain. J Biol Chem 270:7795-7798.

Brennan C, Phillips HS, Landis SC (1996) p75 expression affects the NGF dependency of sympathetic neuron survival in transgenic mice. Soc Neurosci Abstr 22:300.20.
Carroll SL, Silos-Santiago I, Frese SE, Ruit KG, Milbrandt J, Snider WD (1992) Dorsal root ganglion neurons expressing trk are selectively sensitive to NGF deprivation in utero. Neuron 9:779-788.

Carter BD, Kaltschmidt C, Kaltschmidt B, Offenhauser N, Bohmmatthaei R, Baeuerle PA, Barde YA (1996) Selective activation of nf-kappa B by nerve growth factor through the neurotrophin receptor $\mathrm{p} 75$. Science 272:542-545.

Casaccia-Bonnefil P, Carter BD, Dobrowsky RT, Chao MV (1996) Death of oligodendrocytes mediated by the interaction of nerve growth factor with its receptor p75. Nature 383:716-719.

Chapman BS (1995) A region of the $75 \mathrm{kDa}$ neurotrophin receptor homologous to the death domains of TNFR-I1 and Fas. FEBS Lett 374:216-220.

Chinnaiyan AM, O'Rourke K, Tewari M, Dixit VM (1995) FADD, a novel death domain-containing protein, interacts with the death domain of Fas and initiates apoptosis. Cell 81:505-512.

Chinnaiyan AM, O'Rourke K, Yu GL, Lyons RH, Garg M, Duan DR, Xing L, Gentz R, Ni J, Dixit VM (1996) Signal transduction by DR3, a death domain-containing receptor related to TNFR-1 and CD95. Science 274:990-992.

Coggeshall RE (1992) A consideration of neuronal counting methods. Trends Neurosci 15:9-13.

Coggeshall RE, Lekan HA (1996) Methods for determining numbers of cells and synapses: a case for more uniform standards of review. J Comp Neurol 364:6-15.

Crowley C, Spencer SD, Nishimura MC, Chen KS, Pitts MS, Armanini MP, Ling LH, McMahon SB, Shelton DL, Levinson AD, Phillips HS (1994) Mice lacking nerve growth factor display perinatal loss of sensory and sympathetic neurons yet develop basal forebrain cholinergic neurons. Cell 76:1001-1011.

Davies AM, Lee KF, Jaenisch R (1993) p75-deficient trigeminal sensory neurons have an altered response to NGF but not to other neurotrophins. Neuron 11:565-574.

Dobrowsky RT, Werner MH, Castellino AM, Chao MV, Hannun YA (1994) Activation of the sphingomyelin cycle through the low affinity neurotrophin receptor. Science 265:1596-1598.

Dobrowsky RT, Jenkins GM, Hannun YA (1995) Neurotrophins induce sphingomyelin hydrolysis-modulation by co-expression of $\mathrm{p} 75^{\mathrm{ntr}}$ with trk receptors. J Biol Chem 270:22135-22142.

Frade JM, Rodriguez-Tebar A, Barde Y-A (1996) Induction of cell death by endogenous nerve growth factor through its p75 receptor. Nature 383:166-168.

Gloster A, Wu W, Speelman A, Weiss S, Causing C, Pozniak C, Reynolds B, Chang E, Toma JG, Miller FD (1994) The T $\alpha 1 \alpha$-tubulin promoter specifies gene expression as a function of neuronal growth and regeneration in transgenic mice. J Neurosci 14:7319-7330.

Greene LA, Kaplan DR (1995) Early events in neurotrophin signaling via Trk and p75 receptors. Curr Opin Neurobiol 5:579-587.

Hempstead BL, Martin-Zanca D, Kaplan DR, Parada LF, Chao MV (1991) High-affinity NGF binding requires co-expression of the trk proto-oncogene and the low-affinity NGF receptor. Nature 350:678-683.

Hempstead BL, Rabin SJ, Kaplan L, Reid S, Parada LF, Kaplan DR (1992) Overexpression of the trk tyrosine kinase rapidly accelerates nerve growth factor-induced differentiation. Neuron 9:883-896.

Hsu H, Shu HB, Pan MG, Goeddel DV (1996) TRADD-TRAF2 and TRADD-FADD interactions define two distinct TNF receptor 1 signal transduction pathways. Cell 84:299-308.

Ip NY, Stitt TN, Tapley P, Klein R, Glass DJ, Fandl J, Greene LA, Barbacid M, Yancopoulos GD (1993) Similarities and differences in the way neurotrophins interact with the trks in neuronal and nonneuronal cells. Neuron 10:137-149.

Kaplan DR, Matsumoto K, Lucarelli E, Thiele CJ (1993) Induction of trkB by retinoic acid mediates biologic responsiveness to BDNF and differentiation of human neuroblastoma cells. Neuron 11:321-331.

Klein R (1994) Role of neurotrophins in mouse development. FASEB J 8:738-744.

Lee K-F, Li E, Huber J, Landis SC, Sharpe AH, Chao MV, Jaenisch R (1992) Targeted mutation of the gene encoding the low affinity NGF receptor leads to deficits in the peripheral sensory nervous system. Cell 69:737-749.

Nagata S (1997) Apoptosis by death factor. Cell 88:355-366.

Radeke MJ, Misko TP, Hsu C, Herzenberg LA, Shooter EM (1987) Gene transfer and molecular cloning of the rat nerve growth factor receptor. Nature 325:593-597. 
Ruit KG, Elliott JL, Osborne PA, Yan Q, Snider WD (1992) Selective dependence of mammalian dorsal root ganglion neurons on nerve growth factor during embryonic development. Neuron 8:573-587.

Singh S, Aggarwal BB (1995) Protein-tyrosine phosphatase inhibitors block tumor necrosis-dependent activation of the nuclear transcription factor NF-kappa B. J Biol Chem 270:10631-10639.

Tartaglia LA, Ayres TM, Wong G, Goeddel DV (1993) A novel domain within the $55 \mathrm{kd}$ TNF receptor signals cell death. Cell 74:845-853.

Tetzlaff W, Alexander SW, Miller FD, Bisby MA (1991) Response of facial and rubrospinal neurons to axotomy: changes in mRNA expression for cytoskeletal proteins and GAP-43. J Neurosci 11:2528-2544.

Vanderzee CEEM, Ross GM, Riopelle R, Hagg T (1996) Survival of cholinergic forebrain neurons in developing p75(NGFR)-deficient mice. Science 274:1729-1732.

Verdi JM, Birren SJ, Ibanez CF, Persson H, Kaplan DR, Benedetti M, Chao MV, Anderson DJ (1994) p75 ${ }^{\text {LNGFR }}$ regulates Trk signal transduction and NGF-induced neuronal differentiation in MAH cells. Neuron 12:733-745.

von Bartheld CS, Kinoshita Y, Prevette D, Yin QW, Oppenheim RW, Bothwell M (1994) Positive and negative effects of neurotrophins on the isthmo-optic nucleus in chick embryos. Neuron 12:639-654.

Westwick JW, Brenner DA (1995) Methods for analyzing c-jun kinase. Methods Enzymol 255:342-359.

Wu W, Gloster A, Miller FD (1997) Transcriptional repression of the growth-associated Ta1 $\alpha$-tubulin gene by target contact. J Neurosci Res 48:477-487. 